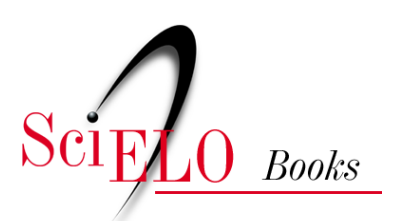

\title{
Policy \\ O dentista e o mercado de trabalho
}

\author{
Lana Bleicher
}

BLEICHER, L. O dentista e o mercado de trabalho. In: CHAVES, S.C.L. Política de saúde bucal no Brasil: teoria e prática [online]. Salvador: EDUFBA, 2016, pp. 255-272. ISBN 978-85-232-2029-7. https://doi.org/10.7476/9788523220297.0010.

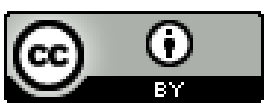

All the contents of this work, except where otherwise noted, is licensed under a Creative Commons Attribution 4.0 International license.

Todo o conteúdo deste trabalho, exceto quando houver ressalva, é publicado sob a licença Creative Commons Atribição 4.0. 


\section{O dentista e o mercado de trabalho}

Lana Bleicher

\section{Apresentação}

Este capítulo cumpre dois objetivos: aproximar o estudante de graduação ao tema do mercado de trabalho do dentista e apresentar o cenário atual da odontologia suplementar. Dessa forma, é possível registrar que as duas partes em que se encontra dividido apresentam estrutura e linguagem diferentes. A primeira, por cumprir uma finalidade didática, retoma alguns clássicos da área, apresentando-os em linguagem acessível. A segunda atualiza dados do setor, percorre uma literatura mais atual e traz elementos para reflexão.

\section{O dentista}

É corrente na literatura, embora não consensual, a noção de que a odontologia no Brasil se origina a partir das práticas dos barbeiros. (MARTINO; BOTAZZO; ZILBOVICIUS, 2010) Até o século XIX, esses trabalhadores não se limitavam a cortar cabelo e fazer barba, mas também realizavam pequenas cirurgias, sangravam, aplicavam ventosas e sanguessugas e extraíam dentes. (FIGUEIREDO, 1999) Aos poucos, essa multiplicidade de atividades foi sendo abandonada, mas barbeiros coexistiram com médicos cirurgiões e dentistas ainda durante certo tempo.

Pimenta (2004) localiza que, no início do século XIX, as práticas de cura próprias das camadas sociais subalternas eram reconhecidas, pois o Estado 
expedia autorizações para médicos, cirurgiões e boticários, mas também emitia licenças para parteiras, sangradores e curandeiros. Médicos detinham mais prestígio que boticários e cirurgiões - estes sob o estigma do trabalho manual, em contato com o sangue. Parteiras e sangradores eram as ocupações mais subalternas. Embora essas diferentes categorias tenham partilhado um mesmo período histórico, em geral direcionavam suas práticas a setores diferentes da sociedade. As classes dominantes usufruíam da medicina praticada por médicos e cirurgiões formados e institucionalizados, enquanto as camadas subalternas recorriam aos barbeiros, sangradores, dentistas e curandeiros, em geral não formados e marginalizados. (MARTINO; BOTAZZO; ZILBOVICIUS, 2010) Não é à toa que Figueiredo (1999) aponta, ao estudar os barbeiros do século XIX, que todos eram homens pardos ou negros, alguns livres, outros escravos.

Com a instituição no Brasil do ensino superior de odontologia em 1884, ocorreu um processo de elitização da profissão, pois a exigência de exames, a frequência ao curso de dois anos, pagamento de taxas e mensalidades expulsou as camadas populares dessa prática. (MOTT et al., 2008) A partir daí, ocorre uma luta entre os profissionais formados para restringir o campo de atuação dos não outorgados. Tal fenômeno pode ser melhor compreendido a partir da Sociologia das Profissões, da qual Freidson (1996) é um dos teóricos mais conhecidos.

De acordo com Freidson (1996), profissões se distinguem das demais ocupações por serem um tipo específico de trabalho especializado. Freitas (2007) salienta que as profissões em geral detêm um conhecimento muito específico que não é acessível ao restante da sociedade, geralmente adquirido por uma formação longa. Isso dá a possibilidade àqueles que a exercem de deter o monopólio do conhecimento e dessa forma ter controle sobre seu próprio trabalho. Tipicamente, dentistas dominam o tratamento odontológico do diagnóstico à alta e não precisam submeter seu trabalho ao julgamento ou à autorização de outra profissão. Assim, no que se refere à prática clínica, o dentista em geral tem autonomia. Mas será que, nas suas relações de trabalho, também é possível constatar tal autonomia?

\section{Tipologias das inserções no mercado de trabalho}

Uma obra fundamental sobre o trabalho do médico foi escrita por Cecília Donnangelo em 1975. O livro Medicina e sociedade: o médico e seu mercado de trabalho influenciou gerações de pesquisadores e é referência também para estudiosos 
do mercado do trabalho dos dentistas. Uma grande contribuição deixada pela autora foi a tipologia pela qual ela classifica as modalidades de inserção no mercado de trabalho. Para fazer essa classificação, são utilizados três critérios.

O primeiro critério é o controle sobre a clientela. Em outras palavras, é a resposta à pergunta: esses pacientes, são pacientes de quem? É o médico (ou dentista) quem atrai e mantém a clientela? No caso dos profissionais que trabalham para empresas (hospitais e clínicas), o paciente é vinculado a estas e, se o profissional for trocado, muito provavelmente a relação entre profissional e usuário será desfeita. O segundo critério é a posse dos meios materiais de trabalho. Há profissionais que são proprietários dos seus equipamentos, insumos e espaço de trabalho. Em outros casos, esses meios pertencem a quem contrata os profissionais. Por fim, o terceiro critério é a liberdade na fixação do preço do trabalho. Profissionais que atendem diretamente sua clientela podem estabelecer o valor de seus honorários, em negociação direta com a pessoa que irá desembolsar o pagamento. Quando dentistas são empregados, o valor a ser cobrado é estipulado pela empresa e é ela quem recebe do usuário.

\section{Modalidades fundamentais}

Assim, a modalidade mais conhecida de inserção no mercado de trabalho para médicos e dentistas é a autônoma: aquela em que o profissional detém o controle sobre a clientela, os meios materiais de trabalho e a liberdade na fixação do preço do trabalho. Apesar dessa ser a forma tradicional pela qual médicos e dentistas se inseriram no mercado de trabalho durante gerações, ela não é a única. A forma autônoma ainda tem muita importância simbólica, pois é a maneira como em geral a sociedade e os profissionais se veem.

Outra modalidade existente é a do assalariado, aquele que vende a sua força de trabalho, sendo remunerado por quem detém os meios de trabalho. Enquanto o autônomo vende um serviço ao paciente (um tratamento completo, por exemplo), o assalariado vende horas de sua jornada para aquele que possui a clínica, equipamentos e insumos. Além de não deter os meios de produção, o assalariado também não pode dispor de sua clientela, que foi arregimentada pelo dono do estabelecimento. Caso seja demitido, será simplesmente substituído por outro que seguirá atendendo a clientela. Quanto cada paciente paga pelo atendimento também não é uma decisão do profissional: cabe-lhe apenas receber o salário. Assim, por mais que se conserve certa autonomia clínica em relação ao diagnóstico e liberdade de tratamento, ela nunca é completa. É o 
proprietário, na condição de comprador da força de trabalho, que estabelece as condições sob as quais o atendimento se processa: ritmo, duração, tipos de materiais.

Percebe-se, portanto, que para existir o assalariado, é preciso que exista o assalariador. A este, Donnangelo denomina empresário, mas poderíamos nominar proprietário. Tal como o autônomo, ele também detém o controle sobre a clientela, os meios materiais de trabalho e a liberdade na fixação do preço do trabalho, mas não o faz para si; ele contrata outros médicos ou dentistas. É comum que o profissional autônomo seja empregador de um ou mais auxiliares. Não é essa a condição que faz com que seja classificado como empresário nessa tipologia. Compreendemos por empresário aquele que tem a renda formada fundamentalmente pela diferença que consegue aferir entre aquilo que gasta remunerando os profissionais assalariados e o que arrecada pela cobrança aos pacientes. É o empresário que capta a clientela para a clínica, que estabelece as condições de trabalho.

Cabe evidenciar que essa tipologia apresenta modelos para interpretação sociológica da realidade e não está delimitada por critérios jurídicos ou contábeis. Donnangelo estabeleceu que estas três modalidades de inserção seriam as "puras" e que havia ainda outras duas "combinadas": autonomia atípica e cooperativa. Bleicher (2011) sugere uma atualização da classificação, conforme a Figura 1.

Figura 1 - Modalidades de inserção no mercado de trabalho, adaptado de Donnangelo (1975)

Modalidades fundamentais

Variações

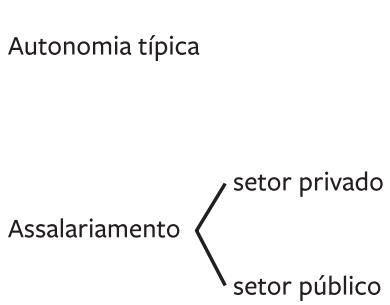

Proprietário
Aluguel de turno

Credenciamento a planos odontológicos

Cooperativa

Trabalho em porcentagem

Trabalhador pejotizado

Estatutário

Celetista

Temporário

Prestador de serviço

Prestador de serviço odontológico

Odontologia Suplementar 


\section{Variações}

O que rotineiramente se chama "aluguel de turno" se refere à situação em que o dentista firma contrato com uma clínica de uma quantidade de horas para fazer uso das instalações do estabelecimento. Muitas vezes, além das instalações, a clínica disponibiliza também o serviço de auxiliares, que, dessa forma, não são contratados diretamente pelo profissional. Assim, com os equipamentos e demais condições necessárias para fazer atendimento, o profissional deve captar a clientela por seus próprios mecanismos, tem liberdade de definir o método de trabalho e liberdade para fixar seus honorários.

Outra modalidade bastante comum é o credenciamento a planos odontológicos. Nesse caso, estamos nos referindo ao profissional que, detendo a posse do consultório, equipamentos e materiais, atende a uma clientela que não foi captada por ele, mas lhe chega a partir de uma operadora de plano de saúde. Ocorre uma sobreposição de características da autonomia típica e do assalariamento, pois o dentista não tem liberdade para fixar o preço de seu trabalho, que é definido pelas tabelas de remuneração das operadoras. Todavia, o fato de o consultório ser seu lhe dá a impressão de que permanece sendo autônomo.

Ainda dentro do espectro da autonomia, podemos localizar as cooperativas, que são sociedades de pessoas cujas forma e natureza jurídicas distinguem-nas de empresas. Não há a figura do dono da cooperativa, todos os cooperados são "donos" da mesma "empresa". A adesão é voluntária e cada associado deve contribuir com uma cota parte de capital para viabilizar a criação e funcionamento da cooperativa. Pessoas estranhas à cooperativa não entram como "investidores", investe quem trabalha nela. Após descontadas as despesas, o que sobra é dividido entre os cooperados. Por não haver um dono, as decisões importantes sobre a cooperativa são tomadas em assembleia onde cada cooperado tem direito a um voto.

Dentro do espectro do assalariamento, é possível encontrar muitas variações e talvez a tipologia apresentada não seja exaustiva. Há muitas formas atípicas de assalariamento. Uma é o trabalho em percentagem, na qual pode haver uma aparência de autonomia, pois o profissional não recebe exatamente um salário, mas uma percentagem do valor que o paciente paga. Há um dono da clínica, que controla a clientela, define em linhas gerais o processo de trabalho e fixa o preço do trabalho. Como o pagamento é vinculado à produtividade $\mathrm{e}$ muitas vezes não há um contrato formal de trabalho, pode parecer que não se trate de assalariamento, mas isso é apenas a aparência. 
Outra forma de assalariamento disfarçado é a pejotização, processo pelo qual o trabalhador é obrigado a se constituir como pessoa jurídica para conseguir vender sua força de trabalho. Como formalmente o profissional é considerado uma empresa, fica descoberto de todos os direitos trabalhistas, vivendo uma situação de muita insegurança. Isso acontece não apenas com dentistas, mas com várias categorias profissionais. Muitas vezes os trabalhadores são demitidos de uma empresa e avisados que, para continuarem desempenhando suas funções, terão que montar uma empresa, ou "abrir pessoa jurídica”, como se diz. O cotidiano do trabalhador segue a mesma rotina: ele continua cumprindo ordens de seu superior imediato, tem determinada carga horária semanal, recebe remuneração. Todavia, por formalmente não ser mais um empregado, mas supostamente o dono de uma empresa contratada, passa a não usufruir de direitos como férias, licença maternidade, $13^{\circ}$ salário etc. Apesar de essa situação contrariar a lei, infelizmente tem se tornado bastante comum.

Para aqueles que trabalham no setor público, há uma variedade extrema de formas de contratação. Infelizmente, os vínculos protegidos não são maioria para os profissionais que atuam no Sistema Único de Saúde (SUS). A pesquisa de Girardi e Carvalho (2008) revelou que, em 2006, 62,7\% dos dentistas brasileiros que trabalhavam no Programa de Saúde da Família tinham postos de trabalho desprotegidos, e 37,3\% tinham empregos protegidos. Os autores classificam como protegidos dois tipos de inserção: o estatutário, que é a relação de trabalho padrão entre servidores civis e a administração pública; e o celetista, aquele que é protegido pela Consolidação das Leis do Trabalho. Ambos têm suporte legal e proteção social, com garantia de direitos trabalhistas. Os postos de trabalho desprotegidos incluem os contratos temporários, contratos como autônomos e outas relações informais, vivenciando falta de direitos sociais e trabalhistas e instabilidade no emprego.

Sobre a modalidade proprietário, é importante destacar que nem sempre o empregador de dentista é um profissional formado em odontologia. Para nossa análise, isso não faz muita diferença, uma vez que nos importa mais entender a morfologia do capital que emprega a força de trabalho dos dentistas. Há basicamente dois tipos de empresas que empregam dentistas: aquelas que vendem diretamente aos usuários o serviço odontológico (prestadora de serviço odontológico) e as que operam planos odontológicos (odontologia suplementar), credenciando dentistas. Os detalhes sobre a chamada odontologia suplementar serão discutidos ao final do capítulo. 


\title{
Precarização social do trabalho
}

A partir do exposto acima, foi possível perceber que, em diversas situações, a inserção do dentista no mercado de trabalho se dá de forma vulnerável e privada de direitos. Para compreender tal fenômeno, é necessário recorrer ao conceito de precarização social do trabalho, que, segundo Thebaud-Mony e Druck (2007, p. 31, grifo nosso), é:

\begin{abstract}
Processo social constituído pela amplificação e institucionalização da instabilidade e da insegurança, expressas nas novas formas de organização do trabalho, onde a terceirização, subcontratação ocupa um lugar central e no recuo do papel do Estado como regulardor do mercado de trabalho e da proteção social através de inovação da legislação do trabalho e previdenciária. Um processo que atinge todos os trabalhadores, independentemente de seu estatuto e que tem levado a crescente degradação das condições de trabalho, saúde e vida dos trabalhadores e da vitalidade da ação sindical.
\end{abstract}

Queremos chamar atenção para o fato de que o fenômeno de precarização não se limita aos trabalhadores já historicamente fragilizados. Essa é uma característica que as autoras fazem questão de pôr em relevo: não se trata de imaginar uma sociedade dual, com incluídos e excluídos. É um fenômeno que, embora afete de maneira diferente grupos distintos de trabalhadores, não pode ser entendido como residual.

Sendo assim, Druck (2011) afirma que existem seis tipos de precarização:

- O primeiro diz respeito à vulnerabilidade das formas de inserção e desigualdades sociais. São formas de inserção precária no mercado de trabalho, sem proteção social, com baixos salários, informalidade e desemprego.

- O segundo se refere à intensificação do trabalho e terceirização. Compreende o prolongamento da jornada de trabalho, a determinação de metas inalcançáveis, o assédio moral no trabalho, a discriminação. Frequentemente a imposição do medo se torna um modelo de gestão. O processo de terceirização permite amplo uso desses "dispositivos gerenciais".

- O terceiro tipo consiste na insegurança e saúde no trabalho, a partir do não oferecimento de condições adequadas de trabalho e de treinamento adequado, resultando em amplo número de acidentes laborais. 
- O quarto tipo é a perda das identidades individual e coletiva, produzida pelo isolamento, perda de vínculos, desvalorização e exclusão. O trabalhador é tratado como descartável e é levado a crer que é o único responsável por sua empregabilidade.

- $\quad$ O quinto se expressa na fragilização da organização dos trabalhadores. 0 enfraquecimento dos sindicatos, a perseguição aos movimentos contestatórios e a judicialização das greves são alguns dos aspectos desse fenômeno.

- O sexto tipo fundamenta-se na condenação e descarte do Direito do TrabaIho através de mudanças na legislação retirando direitos trabalhistas ou na construção de situações em que tais leis se tornem inaplicáveis.

A partir do exposto, é possível perceber que a precarização social do trabalho também atinge os dentistas. É comum que esses profissionais estejam inseridos no mercado a partir de modalidades desprovidas de direitos, sem reconhecimento de vínculo trabalhista, submetidos a situações de alta produtividade, acumulando variadas doenças ocupacionais. A capacidade organizativa dos dentistas tem sido historicamente baixa, mas pode vir a aumentar em futuro próximo. É preocupante que muitas vezes tais situações sejam naturalizadas, como se fossem a obrigatória primeira etapa de toda profissão liberal.

\section{Aspectos quantitativos do mercado de trabalho dos dentistas}

A quantidade de dentistas no Brasil tem aumentado em uma proporção muito superior à taxa de crescimento populacional, um fenômeno que já ultrapassa cinco décadas de duração. Dessa forma, o índice de dentistas para cada 10 mil habitantes tem aumentado ou, inversamente, poderíamos dizer que a quantidade de habitantes por dentistas tem diminuído. Isso ocorre em meio a uma profunda desigualdade de distribuição desses profissionais, mais concentrados na região Sudeste e nos grandes centros urbanos.

Embora o trabalho com proporções (a exemplo de "habitantes por dentista”) seja útil para revelar tendências temporais e apontar desigualdades entre regiões, não é possível estabelecer qual seria a proporção ideal de dentista por população. Populações de tamanhos diferentes podem precisar de mais ou menos dentistas, a depender da prevalência de doenças bucais que apresentem, de diferenças sociodemográficas (tais como composição etária), do modelo de atenção (maior ou menor utilização de tecnologias preventivas) e do processo de trabalho utilizado (maior ou menor delegação de tarefas ao pessoal auxi- 
liar). Nesse sentido, a conhecida "meta da Organização Mundial da Saúde" para quantidade de dentistas não tem muito fundamento. (BLEICHER, 2011)

Ainda que não seja razoável o estabelecimento de metas de profissionais por população, os dados expressos na Tabela 1 parecem indicar que não há deficiência de profissionais no país em termos absolutos. A Tabela 2 revela a desigualdade na distribuição de dentistas pelas macrorregiões. É significativo que, no espaço de 26 anos, as proporções tenham se modificado tão pouco.

Tabela 1 - Número de Cirurgiões-Dentistas (CD), população, índice de CD por 10 mil habitantes e proporção habitante/CD, 1960-2015, Brasil

\begin{tabular}{c|c|c|c|c}
\hline Ano & CD & $\begin{array}{c}\text { População } \\
\text { (em mil) }\end{array}$ & $\begin{array}{c}\text { Índice } \\
\text { CD/10 mil hab. }\end{array}$ & Hab./CD \\
\hline 1960 & 23.000 & 70.191 & 3,28 & 3.052 \\
\hline 1970 & 34.000 & 93.139 & 3,65 & 2.739 \\
\hline 1980 & 61.067 & 119.071 & 5,13 & 1.950 \\
\hline 2000 & 146.677 & 169.799 & 8,64 & 1.158 \\
\hline 2010 & 224.745 & 192.399 & 11,68 & 856 \\
\hline 2015 & 269526 & 204.945 & 13,15 & 760 \\
\hline
\end{tabular}

Fonte: Bleicher (2011); CFO (2015).

Tabela 2 - Número e percentual de dentistas segundo macrorregiões, Brasil, 1982 e 2008

\begin{tabular}{c|c|c|c|c}
\hline \multirow{2}{*}{ Região } & \multicolumn{2}{|c|}{1982} & \multicolumn{2}{c}{2008} \\
\cline { 2 - 5 } & $\mathrm{n}$ & $\%$ & $\mathrm{n}$ & $\%$ \\
\hline Norte & 1.482 & 2,1 & 8.121 & 3,7 \\
\hline Nordeste & 10.057 & 14,3 & 29.714 & 13,5 \\
\hline Sudeste & 43.342 & 61,8 & 129.473 & 59,0 \\
\hline Sul & 11.409 & 16,3 & 34.561 & 15,7 \\
\hline Centrooeste & 3.855 & 5,5 & 17.706 & 8,1 \\
\hline Brasil & $\mathbf{7 0 . 1 4 5}$ & $\mathbf{1 0 0 , 0}$ & $\mathbf{2 1 9 . 5 7 5}$ & $\mathbf{1 0 0 , 0}$ \\
\hline
\end{tabular}

Fonte: Teles (1985); Morita, Haddad e Araujo (2010). 


\section{Odontologia suplementar}

O SUS apresenta três subsistemas: no setor público, há o SUS e, no setor privado, existem o Sistema de Desembolso Direto (SDD) e o Sistema de Atenção Médica Supletiva (SAMS). (CARTAXO; SANTOS, 2007) O SDD é caracterizado pelo atendimento direto aos pacientes, sem intermediação de um terceiro. É composto não apenas por profissionais que exercem a modalidade de autonomia típica, mas também por clínicas dos mais variados portes, qualquer que seja a forma de contratação de seus empregados. O SAMS é definido pela intermediação das operadoras de saúde, ou seja, o paciente não paga diretamente ao profissional que o atende, mas sim à operadora, sendo esta responsável pela remuneração do profissional. É importante salientar que, embora não sejam estatais, o SDD e o SAMS implicam em gastos para o governo, para os quais toda a sociedade contribui. A legislação permite que os gastos privados com saúde sejam deduzidos do imposto de renda, configurando um gasto tributário, uma vez que o Estado, ao não arrecadar, age como se pagasse. A estimativa de gastos tributários somente com planos de saúde relativos à renúncia decorrente do imposto sobre a renda da pessoa física no ano de 2011 foi de $\mathrm{R} \$ 4,8$ bilhões. Despesas que as pessoas fazem no SDD também estão sujeitas a abatimento no imposto de renda. (GARCIA, 2015)

O SAMS é regulado pela Agência Nacional de Saúde Suplementar (ANS), criada pela lei n. ${ }^{\circ} 9.961$ de 2000, mas a existência do setor é anterior a essa data. Já existiam companhias seguradoras e cooperativas odontológicas ao final dos anos 1979, por exemplo. (ANDREAZZI; KORNIS, 2003; VIEIRA; COSTA, 2008) A Lei n. ${ }^{\circ}$ 9.961/00 estabelece que a ANS é um “órgão de regulação, normatização, controle e fiscalização das atividades que garantam a assistência suplementar à saúde" que tem por finalidade “[...] promover a defesa do interesse público na assistência suplementar à saúde, regulando as operadoras setoriais, inclusive quanto às suas relações com prestadores e consumidores, contribuindo para o desenvolvimento das ações de saúde no País”. (BRASIL, 2000)

Alguns autores argumentam que a defesa do "interesse público" pode não ser exatamente o que se observa em vários aspectos da atuação dessa autarquia. Ocke-Reis (2007) considera que o estabelecimento pela ANS de barreiras de entrada a novas operadoras no setor aumenta o poder das empresas que já são líderes e que há quase uma autorregulação deste setor no mercado. Vilarinho (2010) admite que esse fenômeno leva a um abrandamento do rigor de aplicação das leis pela agência. Em pesquisa mais recente, Scheffer e Bahia 
(2015) fizeram um levantamento de doações oficiais de empresas de planos de saúde nas eleições de 2014 e descobriram que o valor de quase $\mathrm{R} \$ 55$ milhões repassados por 40 empresas a 131 candidatos foi quase cinco vezes superior ao investido no ano de 2010. A atuação da ANS não passa incólume a situações como essa. Os autores concluíram que tais doações podem ser consideradas como produtivos investimentos, uma vez que é comum que representantes das operadoras ocupem cargos diretivos na ANS, e que o Governo Federal e Congresso Nacional aprovem medidas que beneficiam economicamente tais empresas.

Os planos de saúde podem ser de contratação individual, caso em que o indivíduo assina contrato diretamente com a operadora, ou coletiva, situação em que o contrato é firmado entre uma pessoa jurídica e a operadora. (ALBUQUERQUE, 2008) Esse último caso abrange as situações em que uma empresa assina o plano de saúde para seus empregados (plano coletivo empresarial). Também existem as situações em que sindicatos e associações possibilitam que seus sindicalizados e associados optem pelos planos de saúde da operadora contratada (plano coletivo por adesão). Pelas normas atuais, o controle do reajuste das mensalidades feito pela ANS atinge somente os planos de contratação individual, que são franca minoria no setor. Para alguns autores, essa situação diminui a capacidade regulatória da agência.

As operadoras de planos de saúde podem ofertar planos médico hospitalares e planos odontológicos, conforme o Quadro 1.

$\begin{aligned} & \text { Quadro 1 - Modalidades de operadoras de planos de saúde segundo as Normas } \\
& \text { Nacionais, Brasil } \\
& \text { (continua) }\end{aligned}$
\begin{tabular}{|c|c|}
\hline Modalidade & Descrição \\
\hline Cooperativa médica & $\begin{array}{r}\text { Sociedades de pessoas sem fins lucrativos que operam planos } \\
\text { privados de assistência à saúde. }\end{array}$ \\
\hline Filantropia & $\begin{array}{r}\text { Entidades sem fins lucrativos que operam planos privados de } \\
\text { assistência à saúde e tenham obtido o certificado de entidade } \\
\text { beneficente de assistência social. }\end{array}$ \\
\hline Autogestão & $\begin{array}{r}\text { Pessoa jurídica de direito privado que opera plano privado } \\
\text { de assistência à saúde exclusivamente aos seguintes } \\
\text { beneficiários: empregados e ex-empregados, aposentados, } \\
\text { sócios, administradores e ex-administradores da entidade de } \\
\text { autogestão, bem como seus familiares e pensionistas. }\end{array}$ \\
\hline
\end{tabular}


Quadro 1 - Modalidades de operadoras de planos de saúde segundo as Normas Nacionais, Brasil

(conclusão)

\begin{tabular}{|c|c|}
\hline Modalidade & Descrição \\
\hline Medicina de grupo & $\begin{array}{r}\text { Empresas ou entidades que operam planos privados de } \\
\text { assistência à saúde, excetuando-se aquelas classificadas nas } \\
\text { modalidades anteriores. }\end{array}$ \\
\hline Cooperativa odontológica & $\begin{array}{r}\text { Sociedades de pessoas sem fins lucrativos, constituídas } \\
\text { conforme o disposto na lei que define a Política Nacional } \\
\text { de Cooperativismo, que operam exclusivamente planos } \\
\text { odontológicos. }\end{array}$ \\
\hline Odontologia de grupo & $\begin{array}{r}\text { Empresas ou entidades que operam exclusivamente planos } \\
\text { odontológicos, excetuando-se aquelas classificadas na } \\
\text { modalidade anterior. }\end{array}$ \\
\hline
\end{tabular}

Fonte: Adaptado de Agência Nacional de Saúde Suplementar (2000) e RN 137/2006.

Os usuários podem contratar planos médico hospitalares, com ou sem odontologia, ou se limitar a planos exclusivamente odontológicos. A distribuição do número de usuários de planos exclusivamente odontológicos entre as modalidades de operadoras pode ser vista na Tabela 3. A modalidade "odontologia de grupo", que tem como exemplo as operadoras Odontoprev e Odontosystem, tem sido, desde o início da Era ANS, a que detém mais beneficiários de planos odontológicos, com quase dois terços do universo. O segundo lugar, todavia, sofreu uma inversão: inicialmente ocupado pela modalidade "cooperativas odontológicas", de que fazem parte as Uniodontos, passou a abrigar a empresas de medicina de grupo, como Amil e Hapvida. Esse fenômeno deve ser melhor estudado e talvez signifique uma dificuldade maior das entidades que se guiam pelos princípios cooperativistas em concorrer com empresas e entidades com fins lucrativos (Tabela 3).

Tabela 3 - Número e percentual de beneficiários de planos exclusivamente odontológicos por modalidade. 2000 e 2015, Brasil

(continua)

\begin{tabular}{l|c|c|c|c}
\hline \multicolumn{1}{c|}{ Modalidade } & \multicolumn{2}{c|}{ Mar./2000 } & \multicolumn{2}{c}{ Jun./2015 } \\
\hline Autogestão & 37.268 & 1,73 & 94.030 & 0,44 \\
\hline Cooperativa médica & 7.759 & 0,36 & 372.596 & 1,73 \\
\hline Filantropia & 52 & 0,00 & 109.675 & 0,51 \\
\hline
\end{tabular}


Tabela 3 - Número e percentual de beneficiários de planos exclusivamente odontológicos por modalidade. 2000 e 2015, Brasil

(conclusão)

\begin{tabular}{l|c|c|c|c}
\hline \multicolumn{1}{c|}{ Modalidade } & \multicolumn{2}{c|}{ Mar./2000 } & \multicolumn{2}{c}{ Jun./2015 } \\
\hline Medicina de grupo & 75.362 & 3,50 & 3.554 .556 & 16,51 \\
\hline $\begin{array}{l}\text { Seguradora especializada em } \\
\text { saúde }\end{array}$ & 157.970 & 7,35 & 834.428 & 3,88 \\
\hline Cooperativa odontológica & 525.516 & 24,44 & 3.206 .085 & 14,89 \\
\hline Odontologia de grupo & 1.346 .616 & 62,62 & 13.355 .097 & 62,04 \\
\hline Total & $\mathbf{2 . 1 5 0 . 5 4 4}$ & $\mathbf{1 0 0 , 0 0}$ & $\mathbf{2 1 . 5 2 6 . 4 6 7}$ & $\mathbf{1 0 0 , 0 0}$ \\
\hline
\end{tabular}

Fonte: Agência Nacional de Saúde Suplementar (2015).

O setor de planos exclusivamente odontológicos tem apresentado extremo dinamismo, com taxas de crescimento superiores ao conjunto da saúde suplementar no período posterior à criação da ANS (Tabela 4). A expansão desse setor ocorreu em meio a um processo de progressiva concentração. Segundo o Caderno de informação da saúde suplementar da ANS, até dezembro de 1999, existiam 670 operadoras de planos exclusivamente odontológicos em atividade. Em junho de 2015, esse número foi reduzido a 377. (AGÊNCIA NACIONAL DE SAÚDE SUPLEMENTAR, 2015) São valores que contrastam vivamente com o exponencial aumento do número de beneficiários. Soma-se a isto o fato de que a maior operadora odontológica do país tem mais de 30\% dos beneficiários, tal como apontado pela publicação Foco saúde suplementar. (AGÊNCIA NACIONAL DE SAÚDE SUPLEMENTAR, 2014) As consequências dessa concentração de capital ainda não foram suficientemente estudadas. É possível que, mantendo-se essa tendência, os CD vinculados a essas empresas venham a se encontrar em maior desvantagem. 
Tabela 4 - Número de beneficiários e taxa de crescimento do número de beneficiários de planos médicos, com ou sem odontologia, e exclusivamente odontológicos, Brasil, 2003-2015

\begin{tabular}{|c|c|c|c|c|}
\hline \multirow{2}{*}{ Ano } & \multicolumn{2}{|c|}{$\begin{array}{c}\text { Número de beneficiários com } \\
\text { planos }\end{array}$} & $\begin{array}{c}\text { Taxa de crescimento (\%) do número } \\
\text { de beneficiários em relação a } \\
\text { dezembro do ano anterior }\end{array}$ \\
\cline { 2 - 5 } & $\begin{array}{c}\text { Médicos com ou } \\
\text { sem odontologia }\end{array}$ & $\begin{array}{c}\text { Exclusivamente } \\
\text { odontológicos }\end{array}$ & $\begin{array}{c}\text { Médicos com ou } \\
\text { sem odontologia }\end{array}$ & $\begin{array}{c}\text { Exclusivamente } \\
\text { odontológicos }\end{array}$ \\
\hline Jun./03 & 31.715 .480 & 3.877 .443 & 0,85 & 14,96 \\
\hline Jun./04 & 33.064 .858 & 4.744 .203 & 4,25 & 22,35 \\
\hline Jun./05 & 34.357 .440 & 5.815 .727 & 3,91 & 22,59 \\
\hline Jun./06 & 36.067 .336 & 6.690 .145 & 4,98 & 15,04 \\
\hline Jun./07 & 37.871 .485 & 7.860 .029 & 5,00 & 17,49 \\
\hline Jun./08 & 40.368 .599 & 9.904 .243 & 6,59 & 26,01 \\
\hline Jun./09 & 41.682 .920 & 11.926 .215 & 3,26 & 20,42 \\
\hline Jun./10 & 43.713 .704 & 13.943 .063 & 4,87 & 16,91 \\
\hline Jun./11 & 45.735 .629 & 15.842 .552 & 4,63 & 13,62 \\
\hline Jun./12 & 46.899 .715 & 18.003 .721 & 2,55 & 13,64 \\
\hline Jun./13 & 48.432 .584 & 19.068 .016 & 3,27 & 5,91 \\
\hline Jun./14 & 49.998 .277 & 20.514 .259 & 3,23 & 7,58 \\
\hline Jun./15 & 50.516 .992 & 21.526 .467 & 1,04 & 4,93 \\
\hline
\end{tabular}

Fonte: Agência Nacional de Saúde Suplementar (2015).

É comum a insatisfação de CD com as operadoras de planos odontológicos, em geral apontando para a perda da autonomia (FREITAS, 2007) e diminuição de rendimentos. (CARTAXO; SANTOS, 2007) Há denúncias de diminuição dos valores pagos por procedimentos e glosas indevidas. (BLEICHER, 2011) Nesse tema, cabe recorrer a uma publicação da ANS intitulada Guia prático da contratualização. (AGÊNCIA NACIONAL DE SAÚDE SUPLEMENTAR, 2013) O dentista que se credencia a uma operadora de plano de saúde deve formalizar a relação comercial por meio do contrato que especifique quais são as obrigações e os deveres das partes. É muito importante que os dentistas estejam protegidos por contratos. As operadoras que por ventura não formalizarem essa relação estarão sujeitas a sanções e multas. O descumprimento desse contrato por qualquer das partes gera a possibilidade de indenização. 
O critério de reajuste dos valores dos procedimentos a serem pagos aos dentistas credenciados deve estar expresso de forma objetiva no contrato, que deve especificar a periodicidade e a forma do reajuste (por exemplo, estabelecendo um índice inflacionário vigente que seja de conhecimento público). Não são permitidas fórmulas de cálculo de reajuste em que o valor contratado seja mantido ou reduzido. A ANS entende que não tem competência legal para definir os preços constantes na tabela remuneratória das operadoras de saúde nem de interferir em processos de glosa e falta de pagamento pelas operadoras aos prestadores. Fica evidente que a legislação pressupõe que a relação existente entre dentistas e operadoras é um assunto de natureza comercial. Nesse raciocínio, não haveria uma parte em desvantagem que mereceria de proteção à desigualdade de poder.

\section{Considerações finais}

O mercado de trabalho do dentista sofreu profundas alterações nas últimas décadas, que vão além do mero crescimento do número de profissionais. Houve uma complexificação desse mercado, com o surgimento de diversas modalidades de inserção. É usual o acúmulo de mais de uma modalidade de inserção no mercado, sobretudo entre dentistas jovens. Há um processo de assalariamento que se expressa nas formas mais precarizadas de contratação. Isso ocorre com a persistência de uma imagem de "profissão liberal" que dificulta uma resistência por parte daqueles que a exercem.

No outro polo desse processo, aquele que compra a força de trabalho do dentista, transformações importantes também ocorrem. Após a criação da ANS, houve um crescimento expressivo dos planos odontológicos, com o surgimento de operadoras de abrangência nacional. Esse mercado se tornou mais concentrado e apresenta problemas próprios de um modelo que toma a saúde como mercadoria, tal como a captura da agência reguladora.

\section{Referências}

AGÊNCIA NACIONAL DE SAÚDE SUPLEMENTAR. Dados Gerais. Disponível em: <http://www.ans.gov.br/perfil-do-setor/dados-gerais> Acesso em: 21 out. 2015.

AGÊNCIA NACIONAL DE SAÚDE SUPLEMENTAR. RDC $n^{0}$ 39, de 27 de outubro de 2000. Disponível em: < http://www.ans.gov.br/component/ legislacao/?view=legislacao\&task=TextoLei\&format=raw\&id=380> Acesso em: 19 out. 2015 . 
AGÊNCIA NACIONAL DE SAÚDE. RN n ${ }^{\circ}$ 137, de 14 de novembro de 2006. Disponível em: <http://www.ans.gov.br/component/ legislacao/?view=legislacao\&task=TextoLei\&format=raw\&id=MTExNw==>. Acesso em: 13 jun. 2016.

AGÊNCIA NACIONAL DE SAÚDE SUPLEMENTAR. Caderno de Informação da Saúde Suplementar: beneficiários, operadors e planos. Ano 9, n. 2, jun. 2015. Disponível em $<$ http://www.ans.gov.br/materiais-publicados/periodicos>. Acesso em: 21 out. 2015.

AGÊNCIA NACIONAL DE SAÚDE SUPLEMENTAR. Foco em saúde suplementar. 2014. Disponível em: <http://www.ans.gov.br/materiais-publicados/periodicos>. Acesso em: 21 out. 2015 .

AGÊNCIA NACIONAL DE SAÚDE SUPLEMENTAR. Reajuste de mensalidade: conceitos básicos, reajuste por variação de custos, reajuste por mudança de faixa etária. 2. ed. rev. ampl, 2005.

ALBUQUERQUE, C. et al . A situação atual do mercado da saúde suplementar no Brasil e apontamentos para o futuro. Ciência \& saúde coletiva, Rio de Janeiro, v. 13, n. 5, out. 2008.

ANDREAZZI, M. F. S.; KORNIS, G. E. M. Transformações e desafios da atenção privada em saúde no Brasil nos anos 90. Physis, v. 13, n. 1, p. 157-191, 2003.

BLEICHER, L. Autonomia ou assalariamento precário?: o trabalho dos cirurgiões- dentistas na cidade de Salvador. 2011. 289 f. Tese (Doutorado em Sociologia) - Universidade Federal da Bahia, Faculdade de Filosofia e Ciências Humanas, Salvador, 2011.

BRASIL. Lei n. 9961, de 28 de janeiro de 2000. Cria a Agência Nacional de Saúde Suplementar - ANS e dá outras providências. Disponível em: <http://www.planalto.gov.br/ ccivil_03/Leis/L9961.htm>. Acesso em: 17 out. 2015.

BRASIL. Lei n. 5.764, de 16 de dezembro de 1971. Define a Política Nacional de Cooperativismo, institui o regime jurídico das sociedades cooperativas, e dá outras providências. Disponível em: <http://www.planalto.gov.br/ccivil_03/LEIS/L5764.htm>. Acesso em: 17 out. 2015.

CARTAXO, J. L. S.; SANTOS, M. L. R. Estudo da satisfação do usuário de planos de saúde odontológicos em Salvador no ano de 2004. Revista Baiana de Saúde Pública, Salvador, v. 1, n. 31, p. 25-37, 2007

DONNANGELO, M. C. F. Medicina e sociedade: o médico e seu mercado de trabalho. São Paulo: Pioneira, 1975.

DRUCK, G. Trabalho, precarização e resistências: novos e velhos desafios? Caderno CRH, Salvador, v. 24, n. 1, p. 37-57, 2011.

FIGUEIREDO, B. G. Barbeiros e cirurgiões: atuação dos práticos ao longo do século XIX. Hist. cienc. saúde-Manguinhos, Rio de Janeiro, v. 6, n. 2, p. 277-291, out. 1999. 
FONSECA, F. Dimensões críticas das políticas públicas. Cad. EBAPE.BR, v. 11, n. 3, artigo 5, Rio de Janeiro, set./nov. 2013.

FREIDSON, E. Para uma análise comparada das profissões: a institucionalização do discurso e do conhecimento formais. Revista Brasileira de Ciências Sociais, São Paulo, ano 11, n. 31, jun. 1996.

FREITAS, C. H. S. de M. Dilemas no exercício profissional da Odontologia: a autonomia em questão. Interface: Comunicação, Educação e Saúde, Botucatu, v. 11, n. 21, p. 25-38, 2007.

GARCIA, L. P. et al. Gastos com planos de saúde das famílias brasileiras: estudo descritivo com dados das Pesquisas de Orçamentos Familiares 2002-2003 e 2008-2009. Ciência \& Saúde Coletiva, Rio de Janeiro, v. 20, n. 5, p. 1425-1434, maio, 2015.

GIRARDI, S. N.; CARVALHO, C. L. Trends in labor contracting in the Family Health Program in Brazil: a telephone survey. Cahiers de Sociologie et Démographie Médicales, v. 48, p. 271-288, 2008.

IBGE. Projeção da população brasileira. Disponível em: <http://www.ibge.gov.br/home/ popclock_home/iframe_popclock_p_home.html> Acesso em: 17 out. 2015.

MARTINO, L. V. S.; BOTAZZO, C.; ZILBOVICIUS, C. Os caminhos públicos da odontologia paulista no início do século XX. Cadernos de História da ciência. São Paulo, v. 6 n. 1, jan./jul. 2010.

MORITA, M. C.; HADDAD, A. E. ; ARAUJO, M. E. Perfil atual e tendências do cirurgiãodentista brasileiro. Dental Press International: Maringá, 2010. v. 1.

MOTT, M. L. et al .'Moças e senhoras dentistas': formação, titulação e mercado de trabalho nas primeiras décadas da República. Hist. cienc. saúde-Manguinhos, Rio de Janeiro, v. 15, supl., p. 97-116, 2008.

OCKE-REIS, C. O. Os desafios da ANS frente à concentração dos planos de saúde. Ciência \& Saúde Coletiva, v. 12, n. 4, p. 1041-1050, 2007.

PIMENTA, T. S. Transformações no exercício das artes de curar no Rio de Janeiro durante a primeira metade do Oitocentos, História, Ciências, Saúde-Manguinhos, Rio de Janeiro, v. 11, supl. 1, p. 67-92, 2004.

SCHEFFER, M.; BAHIA, L. Representação política e interesses particulares na saúde: a participação de empresas de planos de saúde no financiamento de campanhas eleitorais em 2014. 2015. Disponível em: <http://www.abrasco.org.br/site/wp-content/ uploads/2015/02/Planos-de-Saude-e-Eleicoes-FEV-2015-1.pdf>. Acesso em: 21 ago. 2015.

TELES, J. C. B. Assistência odontológica no país: perspectivas 1. Cadernos de Saúde Pública, Rio de Janeiro, v. 2, n. 1, p. 235-62, 1985.

THÉBAUD-MONY, A.; DRUCK, G. Terceirização: a erosão dos direitos nos trabalhadores na França e no Brasil. In: DRUCK, G.; FRANCO T. A perda da razão social do trabalho: terceirização e precarização. São Paulo: Boitempo, 2007. p. 23-58. Capítulo 2. 
VIEIRA, C.; COSTA, N. R. Estratégia profissional e mimetismo empresarial: os planos de saúde odontológicos no Brasil. Ciência \& Saúde Coletiva, Rio de Janeiro, v. 13, n. 5, p. 15791588, set./out. 2008.

VILARINHO, P. F. A percepção da captura política da saúde suplementar no Brasil. CADERNOS EBAPE.BR, Rio de Janeiro, v. 8, n. 4, p. 694-709, dez. 2010. 